\title{
ORTHOTROPIC MODEL OF ROLLING BEARING IN MODELING LATHE SPINDLE DYNAMICS
}

\author{
JAN TOMASZEWSKI \\ West Pomeranian University of Technology, Department of Mechanical Engineering and Mechatronics, Szczecin, Poland \\ Research and Development Department, Andrychowska Fabryka Maszyn DEFUM S.A., Andrychów, Poland
}

\author{
Pawe€ Dunaj, Bartosz Powaeka, Marcin Jasiewicz \\ West Pomeranian University of Technology, Department of Mechanical Engineering and Mechatronics, Szczecin, Poland \\ e-mail: pawel.dunaj@zut.edu.pl
}

\begin{abstract}
This paper presents a method for simplified modeling of bearing nodes of a lathe spindle using the finite element method. The proposed modeling methodology is based on the use of an orthotropic material model, which is used to reflect the stiffness properties of the bearing, both in the radial and axial directions. The modeling results have been experimentally verified. This resulted in full agreement of the mode shapes, an average relative error of the natural frequency values of $1.48 \%$ and high agreement of the receptance function.
\end{abstract}

Keywords: spindle-bearing system, roller bearing, orthotropic material, lathe, machine tool

\section{Introduction}

Dynamic properties of spindles constitute one of the fundamental aspects considered when designing machine tools (Xi et al., 2018; Ritou et al., 2018). They often have a decisive influence on the functional characteristics of a processing machine (Hu et al., 2018). An incorrectly designed spindle can result in a significant reduction in the productivity and accuracy of the machine (Urbikain et al., 2016). Therefore, it becomes crucial to predict its dynamic properties already at the machine tool design stage (Cao and Altintas, 2007). The way the bearing systems are modeled has a significant influence on the accuracy of mapping the dynamic properties of the spindles (Cao et al., 2018).

Cao and Altintas (2004) presented a methodology for modeling bearing systems of machine tool spindles. The proposed methodology was based on the use of the Timoshenko beam model to map the spindle dynamics. The bearing was modeled as a standard nonlinear finite element based on the Jones bearing model (Jones, 1960), which included centrifugal force and gyroscopic effects from the bearing roller elements. As a result, the developed model enabled a good mapping of the dynamic properties of the real bearing, which was confirmed experimentally.

A similar approach was presented by Rantatalo et al. (2007). The authors presented a method for analyzing transverse vibrations of a milling machine spindle using a finite element model. To model the spindle, the authors used the Timoshenko beam model for rotating elements presented in (Nelson, 1980). The bearing stiffness was determined according to (de Mul et al., 1989), and then included in the matrix describing rotating elements. The modeling resulted in differences of no more than $7 \%$ for the natural frequency values determined computationally and experimentally.

Xi et al. (2019) presented a dynamic model of a spindle bearing system combining both the angular contact ball bearing and floating displacement bearing with the consideration of the spindle housing. In the proposed dynamic model, the dynamic bearing systems models 
were developed by a discrete element method with each bearing component having 6 degrees of freedom. The spindle shaft including the tool holder and cutter was modeled by the finite element method based on Timoshenko beam theory, and the spindle housing was modeled as a rigid beam. The simulated dynamic responses were compared with the results measured in the experiment in both time and frequency domains. Results showed that the simulated responses agreed well with the experimentally measured responses.

$\mathrm{Xu}$ et al. (2020) presented a five-degrees-of-freedom model of angular contact ball bearings and a complete high-speed dynamic model with a combination of spindle-holder-tool joints. The authors analyzed the laws of bearing characteristic parameters changing with a pre-load and bearing speed including the contact angle, normal contact force and axial deformation. Influence of the high speed of angular contact ball bearings was introduced in the form of bearing parameters. Furthermore, nonlinear dynamic responses and stability of the high-speed spindle system at the bearing and tool point were studied.

Cao et al. (2019) presented an investigation of the error motion issue of a machine tool spindle. The authors proposed a complete dynamic model of the spindle system. The roller bearings were modeled using Gupta's theory (Gupta, 1979), which includes i.a. cage interactions, roller skid and skew, and geometrical imperfections of bearing raceways. The spindle shaft was discretized using a rigid body element (Cao et al., 2016) to better couple with the bearing model. The complete dynamic model was subjected to experimental verification showing a good agreement.

This paper presents the process of modeling the dynamic properties of a lathe spindle using the finite element method. The main novelty presented in this paper is the methodology of modeling roller bearings by using an orthotropic material model. The use of the orthotropic material made it possible to accurately reproduce the stiffness properties of the bearings in both radial and axial directions, as confirmed experimentally. Furthermore, using the Guyan reduction method (Guyan, 1965), the influence of the rest of the lathe was included in the spindle dynamics model.

The article is structured as follows: Section 2 presents the methodology of modeling roller bearings using the orthotropic material. Section 3 contains an example of the application of the developed methodology to predict dynamic properties of the lathe spindle and provides a comparison of the modeling results with the experimental ones. A summary and the key conclusion are included in Section 4.

\section{Modeling of bearing nodes using an orthotropic material}

A roller bearing is a component in which there are rolling elements between two bearing rings. The inner ring (1) is rested on a shaft journal or other component. The outer ring (2) is also fixed and positioned firmly in the housing or other supporting element. Rolling elements (3) are placed between the rings and are in contact with their raceways, ensuring that the rings rotate relative to each other. A schematic representation of the design of the roller bearings used in the typical bearing nodes of the lathe spindle is shown in Fig. 1.

Depending on the direction of the load to be carried (axial, radial), rolling bearings are characterized by different stiffness. This property became the basis for the idealization during construction of the replacement bearing model.

Defining different stiffness values in three perpendicular directions is possible by using an orthotropic material model. The strain-stress relationship of such a model for a three-dimensional stress state thus takes the following form (Lempriere, 1968) 

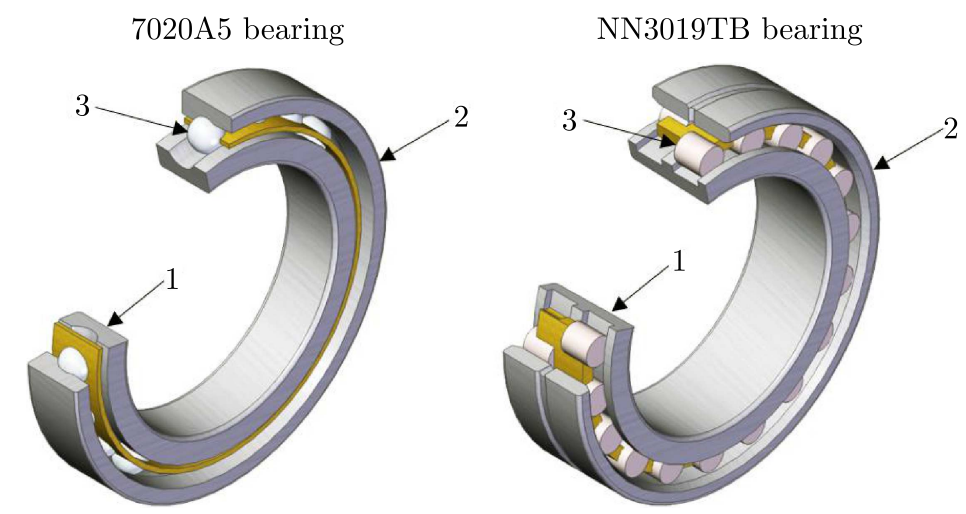

Fig. 1. Schematic representation of the roller bearings used in the bearing nodes of the lathe spindle

$$
\left[\begin{array}{c}
\varepsilon_{x} \\
\varepsilon_{y} \\
\varepsilon_{z} \\
\gamma_{x y} \\
\gamma_{y z} \\
\gamma_{z x}
\end{array}\right]=\left[\begin{array}{cccccc}
\frac{1}{E_{x}} & \frac{-\nu_{y x}}{E_{y}} & \frac{-\nu_{z x}}{E_{z}} & 0 & 0 & 0 \\
0 & \frac{1}{E_{y}} & \frac{-\nu_{z} y}{E_{z}} & 0 & 0 & 0 \\
0 & 0 & \frac{1}{E_{z}} & 0 & 0 & 0 \\
0 & 0 & 0 & \frac{1}{G_{x y}} & 0 & 0 \\
0 & 0 & 0 & 0 & \frac{1}{G_{y z}} & 0 \\
0 & 0 & 0 & 0 & 0 & \frac{1}{G_{z x}}
\end{array}\right]\left[\begin{array}{c}
\sigma_{x} \\
\sigma_{y} \\
\sigma_{z} \\
\tau_{x y} \\
\tau_{y z} \\
\tau_{z x}
\end{array}\right]
$$

where: $G_{i j}$ - Kirchhoff's modulus for the plane $i j, \varepsilon_{i}$ - deformation state component describing volumetric deformation in the direction $i, \gamma_{i j}$ - deformation state component describing form deformation in the plane $i j, \sigma_{i}$-normal stresses in the direction $i, \tau_{i j}$ - tangential stresses in the plane $i j, i, j$ - directions $X, Y, Z$.

The shear modulus for two perpendicular material directions can be approximated according to the Saint-Venant equation (Saint-Venant, 1863)

$$
G_{i j}=\left(\frac{1}{E_{i}}+\frac{1+2 \nu_{j i}}{E_{j}}\right)^{-1}
$$

where $\nu_{j i}$ - Poisson's ratio for deformation in the direction of axis $j$ under load acting in the direction of axis $i$.

In addition, the following assumptions were made regarding the construction and mounting method of the modeled bearings: the bearings are pre-loaded - there is no clearance in the bearings, the loads acting on the bearing do not cause plastic deformation; the system is not affected by a kinematic load (associated with inaccurate mounting of the bearing); there are no errors associated with the geometry of the balls in the system (the balls are perfectly spherical and have the same diameter); the stiffness of the bearings does not depend on the position of the balls. The necessary calculations were carried out in accordance with (Guay and Frikha, 2015).

Based on the assumptions made, a methodology for modeling the bearings using finite elements was proposed. The procedure for determining the values defining the orthotropic model is shown schematically in Fig. 2.

In the first step, a finite element model was built in the form of a toroid with a rectangular cross-section to represent dimensions of the bearing block under consideration. The discretization was performed using six-sided, eight-node isoparametric finite elements. In defining the finite element properties, an isotropic material model was assumed, whose properties were defined in relation to the local coordinate systems of the individual finite elements. For the purposes of this considerations, the material properties for steel were assumed, i.e.

$$
E_{\text {iso }}=210000 \mathrm{MPa} \quad \nu_{\text {iso }}=0.28
$$




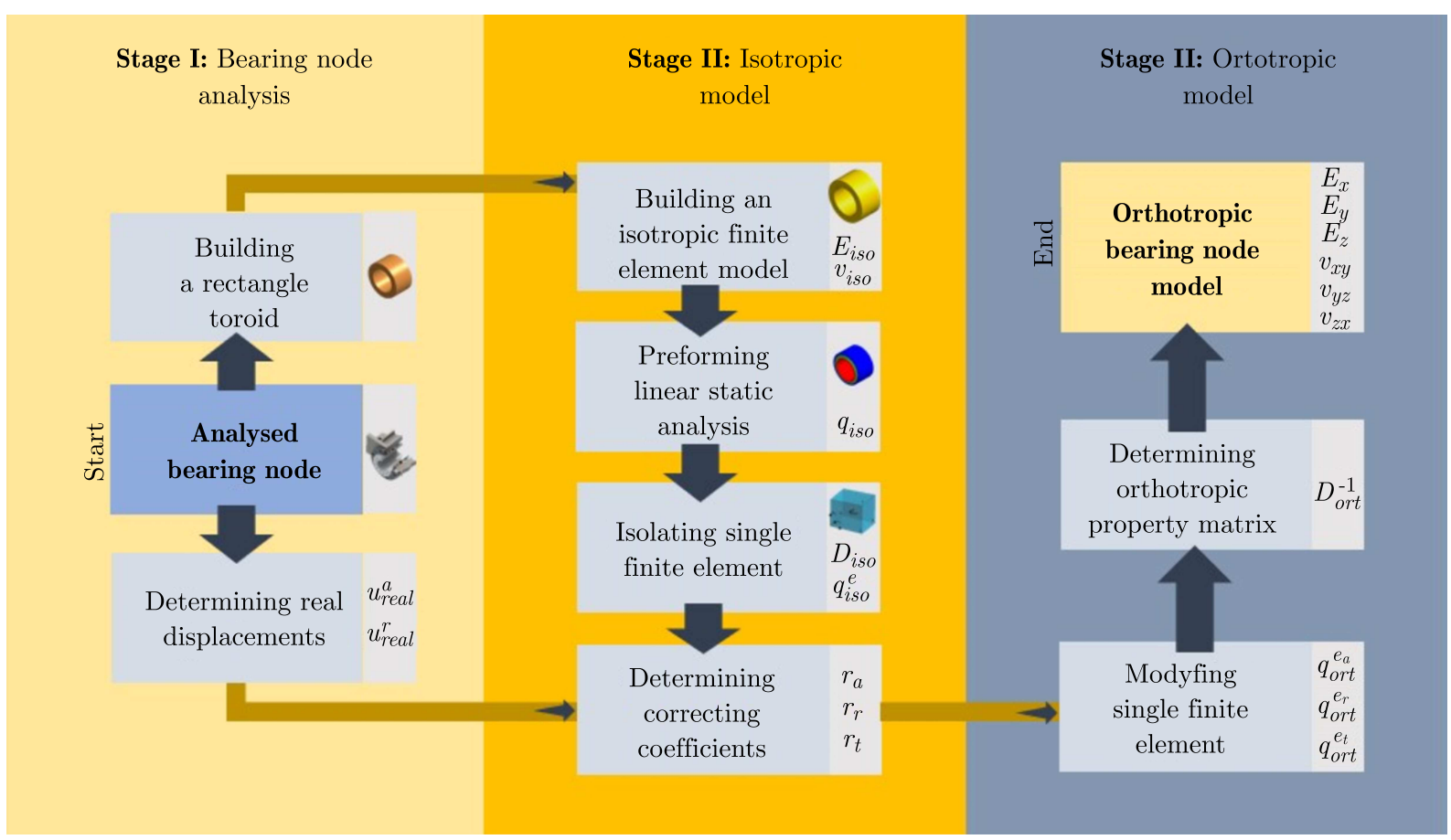

Fig. 2. Schematic representation of the bearing modeling procedure using an orthotropic material model

Further, boundary conditions were defined for the developed model to approximate its interaction with other machine components. The model was then loaded with a unit force of $\mathbf{F}=[1,0,1]$. The method of applying the force and boundary conditions for the bearing node model is shown in Fig. 3.

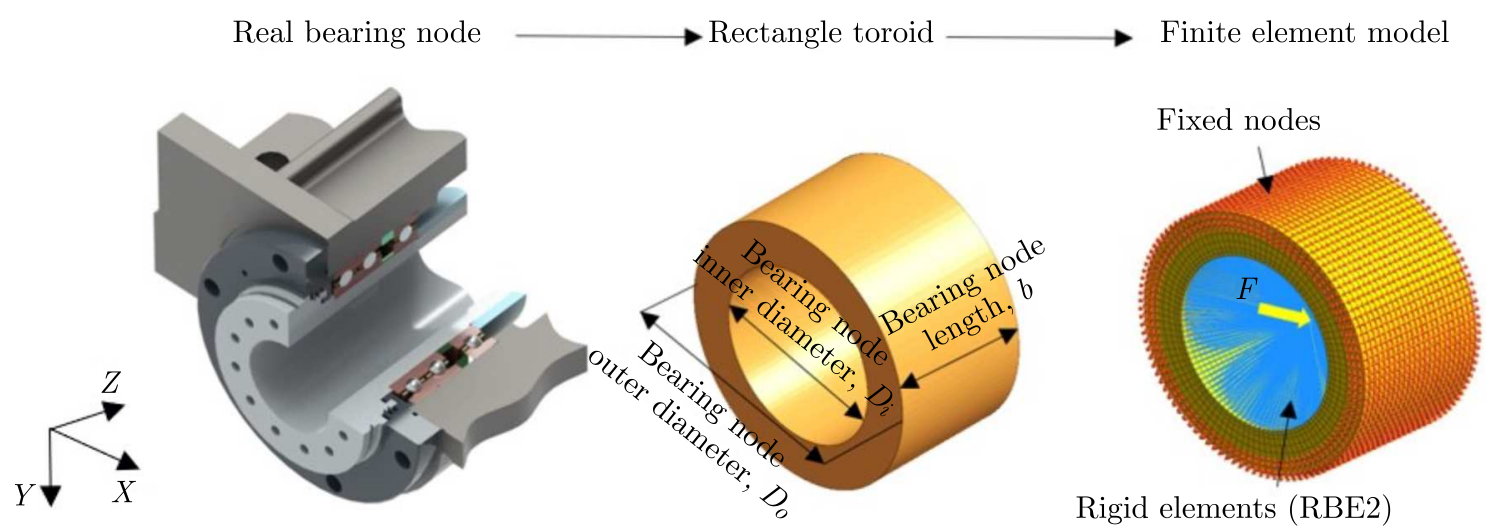

Fig. 3. Process of bearing node discretization: where: $D_{o}$ - bearing node outer diameter, $D_{i}-$ bearing node inner diameter, $b$ - bearing node length

In the next step, the displacement vector $\mathbf{q}_{i s o}$ resulting from the applied unit force was determined. Stress values were then determined for the selected isolated finite element. The element was selected so that it had no defined boundary conditions in the form of single point or multipoint constraints, as shown in Fig. 4.

For an isolated finite element, it can be written as follows

$$
\begin{aligned}
& \varepsilon_{i s o}^{e}=\mathbf{B q}_{i s o}^{e} \\
& \boldsymbol{\sigma}_{i s o}^{e}=\mathbf{D}_{i s o} \varepsilon_{i s o}^{e}
\end{aligned}
$$




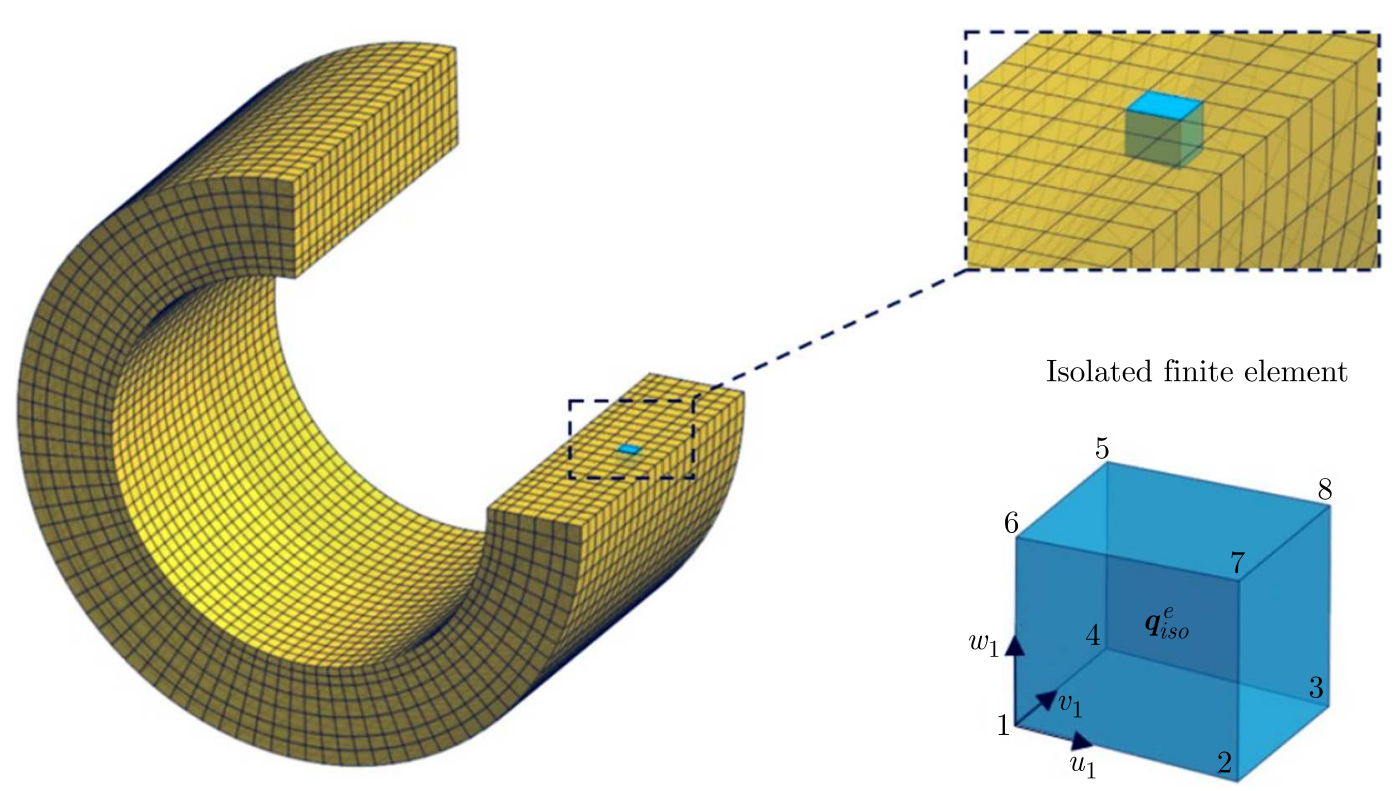

Fig. 4. Isolated finite element

where: $\mathbf{B}$ - shape functions matrix; $\mathbf{D}_{i s o}$ - isotropic material property matrix; $\boldsymbol{\varepsilon}_{i s o}^{e}-$ strain vector for the isotropic element; $\boldsymbol{\sigma}_{i s o}^{e}-$ stress vector for the isotropic element, $\mathbf{q}_{i s o}^{e}-$ displacement vector of an isolated finite element, defined as

$$
\mathbf{q}_{i s o}^{e}=\left[u_{1}, v_{1}, w_{1}, u_{2}, v_{2}, w_{2}, u_{3}, v_{3}, w_{3}, u_{4}, v_{4}, w_{4}, u_{5}, v_{5}, w_{5}, u_{6}, v_{6}, w_{6}, u_{7}, v_{7}, w_{7}, u_{8}, v_{8}, w_{8}\right]^{\mathrm{T}}
$$

Further, it is assumed that the isotropic model built is characterized by the same stress state as the target orthotropic model; only the strains change. According to this assumption, a correction coefficient $r$ which proportionally modifies the stiffnesses at the corresponding degrees of freedom of the isolated finite element can be determined. Dividing the vector $\mathbf{q}_{\text {iso }}^{e}$ into its component vectors containing radial $r$, axial $a$ and tangential $t$ degrees of freedom can be written as

$$
\begin{aligned}
& \mathbf{q}_{i s o}^{e_{a}}=\left[v_{1}, v_{2}, v_{3}, v_{4}, v_{5}, v_{6}, v_{7}, v_{8}\right]^{\mathrm{T}} \quad \mathbf{q}_{i s o}^{e_{r}}=\left[u_{1}, u_{2}, u_{3}, u_{4}, u_{5}, u_{6}, u_{7}, u_{8}\right]^{\mathrm{T}} \\
& \mathbf{q}_{i s o}^{e_{t}}=\left[w_{1}, w_{2}, w_{3}, w_{4}, w_{5}, w_{6}, w_{7}, w_{8}\right]^{\mathrm{T}}
\end{aligned}
$$

This modification is performed as follows

$$
\mathbf{q}_{\text {ort }}^{e_{a}}=r_{a} \mathbf{q}_{i s o}^{e_{a}} \quad \mathbf{q}_{\text {ort }}^{e_{r}}=r_{r} \mathbf{q}_{i s o}^{e_{r}} \quad \mathbf{q}_{\text {ort }}^{e_{t}}=r_{t} \mathbf{q}_{i s o}^{e_{t}}
$$

where: $r_{a}$-axial correction coefficient (axial displacement ratio); $r_{r}$ - radial correction coefficient (radial displacement ratio); $r_{t}$ - correction coefficient. Coefficients $r_{a}$ and $r_{r}$ are determined from the following relationship

$$
r_{a}=\frac{u_{\text {real }}^{a}}{u_{\text {iso }}^{a}} \quad r_{r}=\frac{u_{r e a l}^{r}}{u_{i s o}^{r}}
$$

where: $u_{r e a l}^{a}$ - axial displacement of the actual bearing node; $u_{\text {real }}^{r}$ - radial displacement of the actual bearing node. The displacement values $u_{r e a l}^{a}$ and $u_{r e a l}^{r}$ caused by the unit forces can be determined from the axial $k_{\text {real }}^{a}$ and radial $k_{\text {real }}^{r}$ stiffness values

$$
u_{\text {real }}^{a}=\frac{1}{k_{\text {real }}^{a}} \quad u_{\text {real }}^{r}=\frac{1}{k_{\text {real }}^{r}}
$$


The values $k_{\text {real }}^{a}$ and $k_{\text {real }}^{r}$ can be determined experimentally or, for example, using data from the manufacturer's catalogue. According to (Cao and Altintas, 2004) and (Rantatalo et al., 2007) at the spindle speed lower than $5000 \mathrm{rpm}$, the changing the stiffness of the spindle bearings in relation to the spindle at rest is negligible. In the case of the lathe in question, the upper spindle speed limit is $5000 \mathrm{rpm}$.

It should be noted that the model developed does not allow representation of the free rotation of the bearing block relative to its axis. Attempting to represent free rotation results in singularity of the stiffness matrix of the bearing block model. Accordingly, for the purposes of further analysis, the following was assumed

$$
r_{t}=r_{r}
$$

The values of axial $u_{i s o}^{a}$ and radial $u_{i s o}^{r}$ displacements caused by the unit force $F$ are components of the vector $\mathbf{q}_{i s o}$, and describe the displacements at the point of application of the unit force in the toroidal model (Fig. 3).

Then, the deformation vector for the isolated finite element was determined according to the relationship

$$
\varepsilon_{\text {ort }}^{e}=\mathbf{B q}_{o r t}^{e}
$$

In the next step, the orthotropic matrix $\mathbf{D}_{\text {ort }}$ corresponding to the stiffness of the isolated orthotropic element is determined, this matrix is determined from the relationship

$$
\varepsilon_{\text {ort }}^{e}=\mathbf{D}_{\text {ort }}^{-1} \boldsymbol{\sigma}_{\text {iso }}^{e}
$$

This is tantamount to determining the quantities defining the orthotropic material property matrix i.e., $E_{x}, E_{y}, E_{z}, \nu_{x y}, \nu_{y z}, \nu_{z x}$, which should then be assigned to the toroid model.

Based on the defined procedure (Fig. 2), the models of bearing nodes used in lathe spindles were built. The comparison of the accuracy of mapping of the stiffness in the axial and tangential directions determined for the selected bearing nodes supplemented with relative errors values is shown in Table 1. The designations next to the bearing catalog number in Table 1 mean the bearing contact angle, and so designation A5 means that the contact angle is $25^{\circ}$ and designation $C$ the contact angle is $15^{\circ}$.

\begin{tabular}{|c|c|c|c|c|c|c|c|c|c|}
\hline $\begin{array}{c}\text { Bearing } \\
\text { compo- } \\
\text { nent }\end{array}$ & $\begin{array}{c}\text { Bearing } \\
\text { arrange- } \\
\text { ment }\end{array}$ & $\begin{array}{c}\text { Bearing } \\
\text { node } \\
\text { dimensions } \\
{[\mathrm{mm}]} \\
\end{array}$ & $\begin{array}{c}k_{r e a l}^{a} \\
{[\mathrm{~N} / \mu \mathrm{m}]}\end{array}$ & $\begin{array}{c}k_{\text {real }}^{r} \\
{[\mathrm{~N} / \mu \mathrm{m}]}\end{array}$ & $\frac{k_{\text {real }}^{a}}{k_{\text {real }}^{r}}$ & $\begin{array}{c}k_{o r t}^{a} \\
{[\mathrm{~N} / \mu \mathrm{m}]}\end{array}$ & $\begin{array}{c}k_{o r t}^{r} \\
{[\mathrm{~N} / \mu \mathrm{m}]}\end{array}$ & $\delta_{a}$ & $\delta_{r}$ \\
\hline $\begin{array}{c}\text { 7913A5 } \\
7913 \mathrm{C}\end{array}$ & DB & $\begin{aligned} D_{o} & =\emptyset 90 \\
D_{i} & =\emptyset 65 \\
b & =26\end{aligned}$ & $\begin{array}{c}233.0 \\
104.00\end{array}$ & $\begin{array}{l}466.00 \\
520.00\end{array}$ & $\begin{array}{l}2 \\
5\end{array}$ & $\begin{array}{l}232.96 \\
105.58\end{array}$ & $\begin{array}{l}466.91 \\
566.15\end{array}$ & $\begin{array}{l}0.02 \% \\
1.52 \%\end{array}$ & $\begin{array}{l}0.02 \% \\
5.84 \%\end{array}$ \\
\hline $\begin{array}{c}7020 \mathrm{~A} 5 \\
7020 \mathrm{C}\end{array}$ & DBD & $\begin{aligned} D_{o} & =\emptyset 150 \\
D_{i} & =\emptyset 100 \\
b & =84\end{aligned}$ & $\begin{array}{l}617.00 \\
276.76\end{array}$ & $\begin{array}{l}1287.00 \\
1439.90\end{array}$ & $\begin{array}{c}2.09 \\
5.2\end{array}$ & $\begin{array}{l}616.94 \\
275.86\end{array}$ & $\begin{array}{l}1286.91 \\
1348.64\end{array}$ & $\begin{array}{l}0.01 \% \\
0.32 \%\end{array}$ & $\begin{array}{l}0.01 \% \\
6.33 \%\end{array}$ \\
\hline $\begin{array}{c}7222 \mathrm{~A} 5 \\
7222 \mathrm{C}\end{array}$ & DBD & $\begin{aligned} D_{o} & =\emptyset 200 \\
D_{i} & =\emptyset 110 \\
b & =124\end{aligned}$ & $\begin{array}{l}1065.00 \\
337.41\end{array}$ & $\begin{array}{l}2217.60 \\
1755.50\end{array}$ & $\begin{array}{c}2.09 \\
5.2\end{array}$ & $\begin{array}{l}1065.38 \\
340.11\end{array}$ & $\begin{array}{l}1117.39 \\
1722.47\end{array}$ & $\begin{array}{l}0.02 \% \\
0.79 \%\end{array}$ & $\begin{array}{l}0.01 \% \\
1.89 \%\end{array}$ \\
\hline
\end{tabular}

Table 1. Comparison of the accuracy of mapping of the stiffness in the radial and axial directions determined for selected bearings

When analyzing the modeling results presented in Table 1, it can be noticed that thanks to the proposed modeling procedure it is possible to achieve high accuracy of mapping the radial and axial stiffness of the bearings. 
The proposed method allows for an accurate representation of the stiffness properties of bearing nodes, regardless of their overall dimensions. Moreover, it is possible to accurately reproduce these properties independently of the bearing arrangement.

However, when analyzing the obtained results, it can be noticed that in the case of bearings with a smaller contact angle (type C), and thus a larger ratio $k_{\text {real }}^{a} / k_{\text {real }}^{r}$, the accuracy of the mapping decreases, especially in the case of radial stiffness. It is related to the procedure of determining the parameters of the orthotropic material itself and it concerns the stage of analysis of an isolated finite element. It should be noted that when determining the correction coefficients $r_{r}$ and $r_{a}$, the volumetric and shear strains of the isolated element are considered, and the latter affect the deterioration of the accuracy of the radial stiffness representation. To be precise, the axial stiffness of the bearing node model is similarly determined by both the volumetric and shear components, but in the case of radial stiffness, the shear component is much less important. Since the proposed procedure for determining the parameters of the orthotropic material equally considers the volume and shear strains, it favors the bearings with a lower $k_{\text {real }}^{a} / k_{\text {real }}^{r}$ ratio.

\section{Predicting dynamics of a lathe spindle}

\subsection{Lathe spindle under analysis}

The procedure for modeling the bearing nodes is presented on the example of the spindle of TAE35N rope thread lathe manufactured by AFM DEFUM. A graphical visualization of the spindle under consideration with the bearing nodes under further analysis marked is shown in Fig. 5.

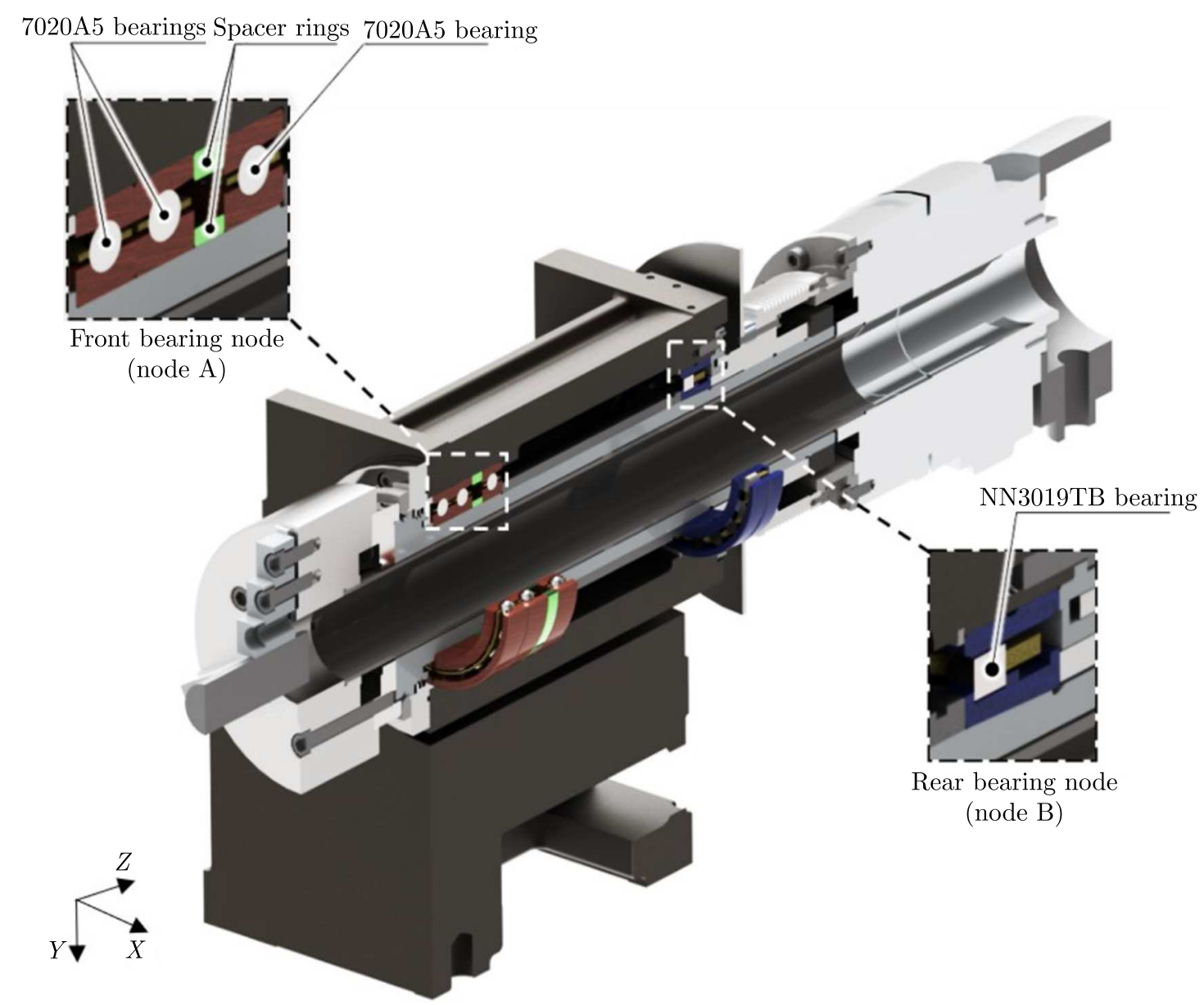

Fig. 5. The lathe spindle under consideration with the bearing node marked 
The front bearing node $\mathrm{A}$ is a locating node operating in the DBD configuration. The node consists of three NSK super-precision angular contact bearings with designation 7020A5 TRDUDMP3 and two spacer rings. The bearings used are characterized by the ability to carry loads in both radial and axial directions. In addition, they provide the possibility of achieving a pre-load in class M (Middle).

The rear bearing node $\mathrm{B}$ is a floating node consisting of a double-row roller bearing manufactured by NSK, with designation NN3019TB KRE44CC0P4. The bearing used is only capable of supporting radial loads.

\subsection{Bearing nodes models}

Based on the proposed modeling method, the orthotropic material properties were defined (Table 2), and the finite element models of the bearing nodes were built (using Midas NFX software). The MAT12 with the local material properties definition model for spatial finite elements was used to map the orthotropic material properties. This coordinate system ensures reduction of the impact of receiving DOF, in the form of rotation of the spindle in relation to the entire headstock.

Table 2. Material property values for orthotropic bearing block models

\begin{tabular}{|c|c|c|}
\hline Property & Node A & Node B \\
\hline \hline$E_{x}$ & $1120 \mathrm{MPa}$ & $7960 \mathrm{MPa}$ \\
\hline$E_{y}$ & $190 \mathrm{MPa}$ & $630 \mathrm{MPa}$ \\
\hline$E_{z}$ & $2290 \mathrm{MPa}$ & $190000 \mathrm{MPa}$ \\
\hline$\nu_{y x}$ & 0.21 & 0.02 \\
\hline$\nu_{z y}$ & 0.21 & 1.33 \\
\hline$\nu_{x z}$ & 0.21 & 0.05 \\
\hline$\nu_{x y}$ & 1.24 & 0.30 \\
\hline$\nu_{y z}$ & 0.07 & 0.05 \\
\hline$\nu_{z x}$ & 0.43 & 1.33 \\
\hline
\end{tabular}

Node A

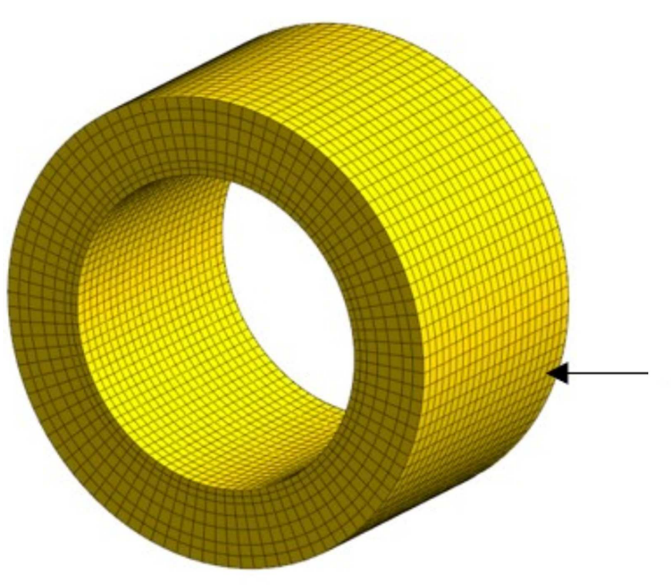

Node B

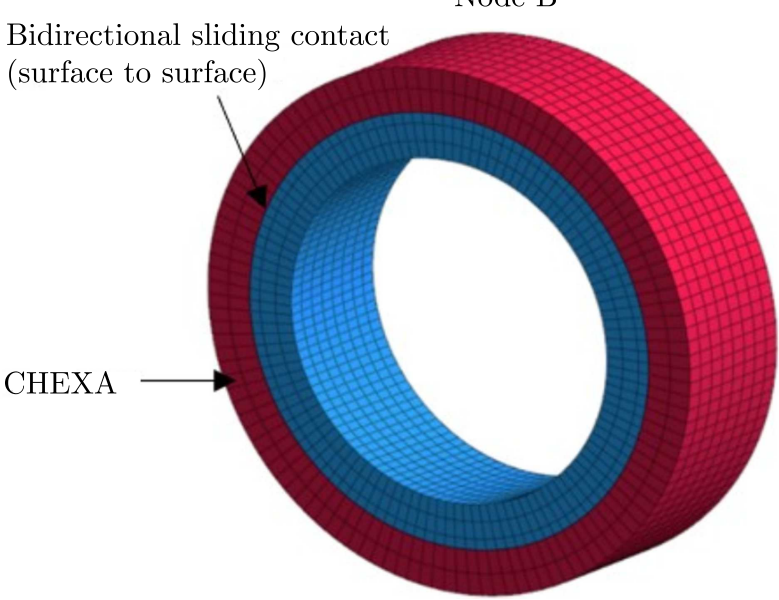

Fig. 6. Developed discrete models of bearing nodes

The discretization was carried out using a structured mesh constructed from six-sided eight-node isoparametric CHEXA finite elements with linear shape functions. In summary, the developed bearing node A model consisted of 15400 finite elements and 63306 degrees of freedom, while the bearing node B model consisted of 4800 finite elements and 25926 degrees of freedom. Discrete models of the analyzed bearing blocks are shown in Fig. 6. 
It should be noted that in the case of the bearing node B, the bearing used does not carry loads in the axial direction, so its finite element model consists of a set of two meshes (blue and red) that can move freely relative to each other in the axial direction. Free movement is ensured by means of surface-to-surface contact of the bidirectional sliding type.

\subsection{Finite element model of a lathe spindle}

The developed bearing block models were used to model the lathe spindle described in Section 3.1. The discretization of other parts of the spindle under consideration was carried out by using six-sided eight-node isoparametric CHEXA finite elements and five sided six-node isoparametric CPENTA finite elements.

To describe the damping properties of the modeled machine tool, a structural damping model was used (Neumark, 1962), according to which the damping matrix $\mathbf{C}$ can be expressed as

$$
\mathbf{C}=j \eta \mathbf{K}
$$

where: $\mathbf{K}$ - finite element model stiffness matrix; $\eta$ - loss factor; $j$ - imaginary unit.

In addition, the spindle model includes the workpiece, which is a steel shaft with diameter of $40 \mathrm{~mm}$, and length of $125 \mathrm{~mm}$, with $60 \mathrm{~mm}$ overhang from the lathe holder.

The lathe spindle does not exist as an independent, isolated component. On the other hand, modeling the entire lathe seems to unnecessarily increase the dimensionality of the model. It was therefore decided to use the Guyan reduction method (Guyan, 1965) to reduce the model of the entire lathe to a set of springs, to which the spindle was then attached.

The purpose of model reduction is to find and $m$ degrees of freedom (DOFs) system preserving the dynamic characteristics of the full model with $n$ DOFs, in which $m \ll n$. The commonly used approach is to approximate the state vector by means of the transformation $\mathbf{q}=\mathbf{T} \mathbf{q}_{R}$, where $\mathbf{T} \in \mathbb{R}^{n \times m}$ and $\mathbf{q}_{R} \in \mathbb{R}^{m \times 1}$

$$
\left.\mathbf{M}_{R} \ddot{(} \mathbf{q}\right)_{R}+\mathbf{K}_{R} \mathbf{q}_{R}=\mathbf{f}_{R}
$$

where the reduced mass $\mathbf{M}_{R}$ and stiffness $\mathbf{K}_{R}$ matrices are

$$
\mathbf{M}_{R}=\mathbf{T}^{\mathrm{T}} \mathbf{M T} \quad \mathbf{K}_{R}=\mathbf{T}^{\mathrm{T}} \mathbf{K} \mathbf{T}
$$

The Guyan reduction consists in reducing the degrees of freedom of the finite element model to degrees of freedom located on the border of the model (master DOFs). The reduction is made by removing slave degrees of freedom defined as being outside the model boundary while master DOFs retain the stiffness and inertia of the model. Partitioning of the state vector in the master and slave DOFs allows are to divide the system matrices into submatrices as follows

$$
\left[\begin{array}{cc}
\mathbf{M}_{m m} & \mathbf{M}_{m s} \\
\mathbf{M}_{s m} & \mathbf{M}_{s s}
\end{array}\right]\left[\begin{array}{c}
\ddot{\mathbf{q}}_{m} \\
\ddot{\mathbf{q}}_{s}
\end{array}\right]\left[\begin{array}{cc}
\mathbf{K}_{m m} & \mathbf{K}_{m s} \\
\mathbf{K}_{s m} & \mathbf{K}_{s s}
\end{array}\right]\left[\begin{array}{c}
\mathbf{q}_{m} \\
\mathbf{q}_{s}
\end{array}\right]=\left[\begin{array}{c}
\mathbf{f}_{m} \\
\mathbf{f}_{s}
\end{array}\right]
$$

where: $\mathbf{q}_{m}$ - master degrees of freedom, $\mathbf{q}_{s}$ - slave degrees of freedom.

Solving the second row in Eq. (3.4) for $\mathbf{q}_{s}$ results in

$$
\mathbf{q}_{s}=-\mathbf{K}_{s s}^{-1}\left[\mathbf{M}_{s m} \ddot{\mathbf{q}}_{m}+\mathbf{M}_{s s} \ddot{\mathbf{q}}_{s}+\mathbf{K}_{s m} \mathbf{q}_{m}\right]
$$

assuming that there are no loads acting on the slave degrees of freedom $\left(\mathbf{f}_{s}=0\right)$ and neglecting the inertia terms, results in the transformation of the state vector for Guyan reduction

$$
\left[\begin{array}{l}
\mathbf{q}_{m} \\
\mathbf{q}_{s}
\end{array}\right]=\left[\begin{array}{c}
\mathbf{I} \\
-\mathbf{K}_{s s}^{-1} \mathbf{K}_{s m}
\end{array}\right] \mathbf{q}_{m}=\mathbf{T} \mathbf{q}_{m}
$$

where $\mathbf{T}$ is the Guyan transformation matrix used to obtain the reduced system matrices.

In summary, the model developed including the component models of the bearing nodes and the workpiece consisted of 157531 elements and had 474501 degrees of freedom. The complete finite element model of the spindle is shown in Fig, 7. 


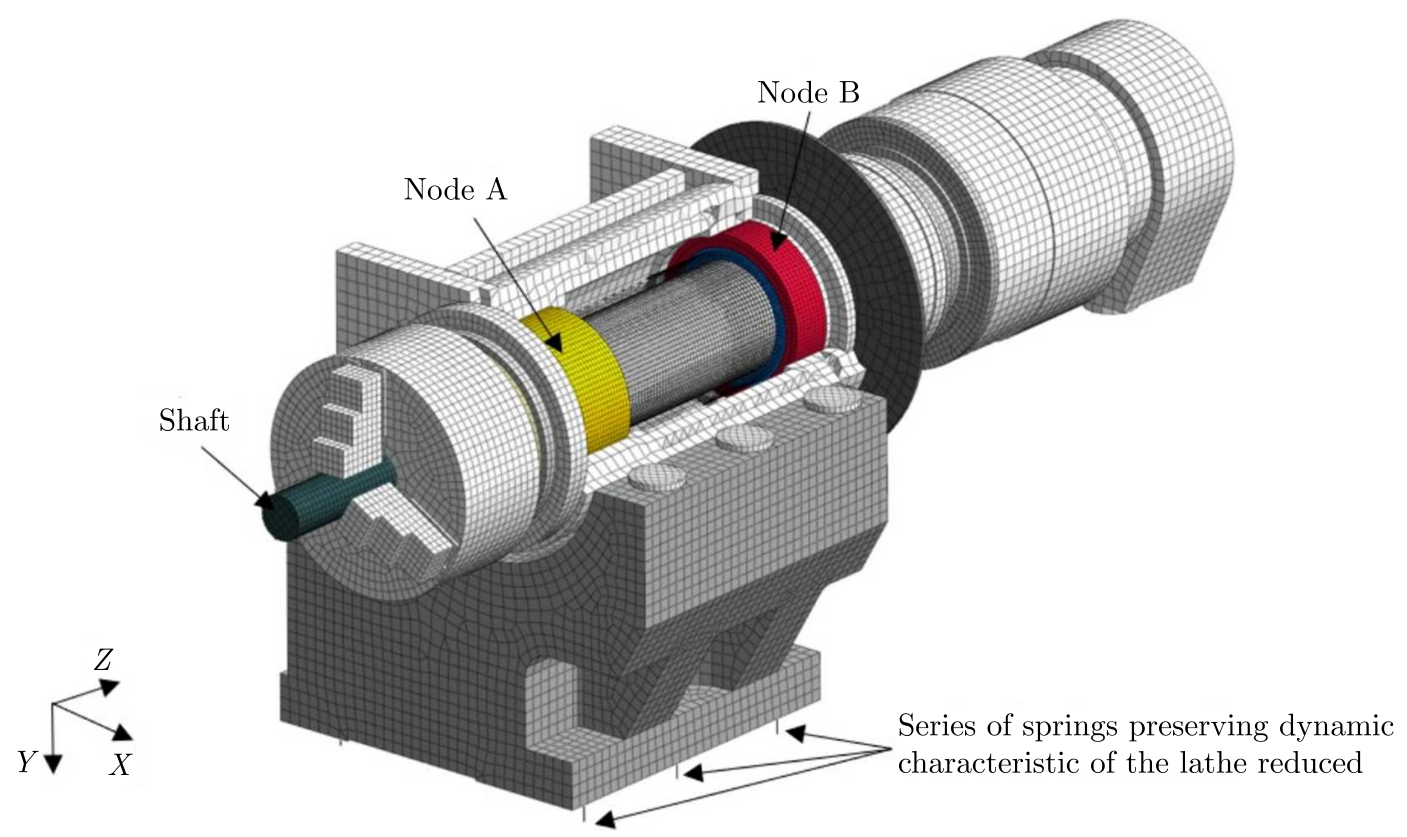

Fig. 7. Discrete model of the lathe spindle under consideration

\subsection{Experimental verification}

To verify the accuracy of the finite element model of the lathe spindle and the developed methodology for modeling the bearing nodes, an experimental modal analysis in the form of an impulse test was carried out.

An experimental modal analysis was carried out for the entire lathe. The excitation was performed using a PCB 086C05 modal hammer, the machine tool was excited at the end of the workpiece successively in three mutually perpendicular directions (corresponding to the coordinate system adopted at the spindle modeling stage). Responses to a given excitation were measured at 31 points with the application of PCB 356A01 triaxial piezoelectric accelerometers. The layout measurement points is presented in Fig. 8.

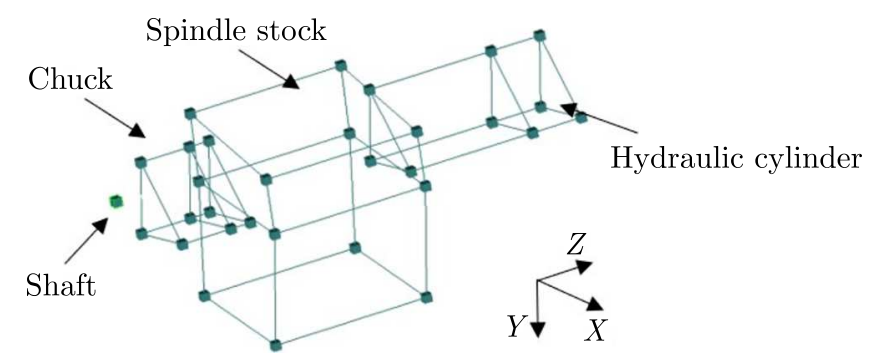

Fig. 8. Measurement points layout

Measurement data acquisition was conducted using Scadas Mobile Vibco and Testlab 2019.1 software. The estimation of the frequency response function was performed with the use of $\mathrm{H}_{1}$ estimator. Other information on the processing of the recorded signals is provided in Table 3 .

As a result, 279 frequency response functions were determined, based on which the parameters of the modal model were estimated (i.e., values of natural frequencies and corresponding mode shapes). The estimation process was carried out using a stabilization diagram and the Polymax algorithm (Peeters et al., 2004).

In the next step, the experimental modal model was validated. This process was based on the analysis of the MAC criterion, which determines the orthogonality of the vibration form vectors. 
Table 3. Parameters of signal acquisition

\begin{tabular}{|l|c|}
\hline \multicolumn{1}{|c|}{ Parameter } & Value \\
\hline \hline Sampling rate & $4096 \mathrm{~Hz}$ \\
\hline Frequency resolution & $0.5 \mathrm{~Hz}$ \\
\hline Signal acquisition time & $2 \mathrm{~s}$ \\
\hline Number of averages & 10 \\
\hline Scaling of frequency response function & global \\
\hline
\end{tabular}

This was done by eliminating interdependent vibration form vectors (a limit value of $10 \%$ was assumed) (Allemang, 2003).

A comparison of natural frequency values determined experimentally and computationally, supplemented with relative error values, is given in Table 4, while a comparison of selected mode shapes is shown in Fig. 9.

Table 4. Comparison of experimentally and computationally determined natural frequencies

\begin{tabular}{|c|c|c|c|}
\hline $\begin{array}{c}\text { Mode } \\
\text { shape }\end{array}$ & \multicolumn{2}{|c|}{ Natural frequency [Hz] } & Relative error \\
\cline { 2 - 3 } & FEM model & Experiment & $\delta[\%]$ \\
\hline \hline 1 & 136.75 & 134.02 & 2.04 \\
\hline 2 & 157.23 & 160.30 & 1.91 \\
\hline 3 & 227.59 & 221.95 & 2.54 \\
\hline 4 & 285.15 & 284.32 & 0.29 \\
\hline 5 & 395.27 & 389.85 & 1.39 \\
\hline 6 & 402.13 & 399.41 & 0.68 \\
\hline \hline \multicolumn{3}{|c|}{ On average } & 1.48 \\
\hline
\end{tabular}

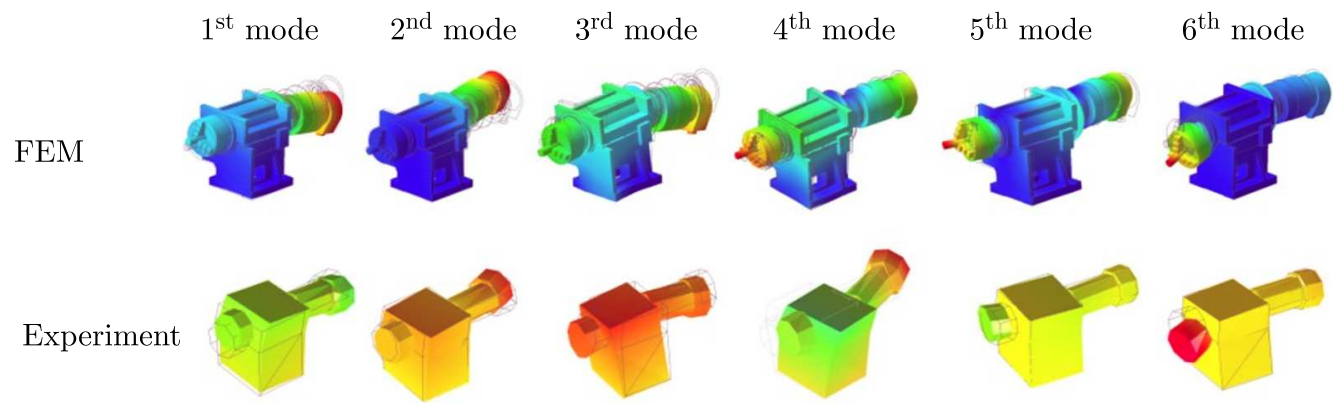

Fig. 9. Comparison of selected mode shapes determined computationally and experimentally

Comparing the computational model with the experimental values of natural frequencies (Table 4), the relative error for different mode shapes did not exceed $2.54 \%$, with an average of $1.48 \%$. In addition, it should be noted that the proposed spindle model shows an agreement of the mode shapes.

Moreover, sensitivity analysis of the mode shapes to the bearing nodes stiffness was performed. It consisted in changing the bearing preload of the node A resulting in a stiffness change - Table 5.

Performed analysis showed that the first four modes are almost independent to the bearing stiffness change (natural frequencies changes did not exceed 2.34\%). However, higher modes switched order, i.e., the fifth mode of the extra light preload model corresponds to the sixth mode of the middle preload model. Thus, it can be stated that the bearing stiffness has a significant influence on spindle dynamics. 

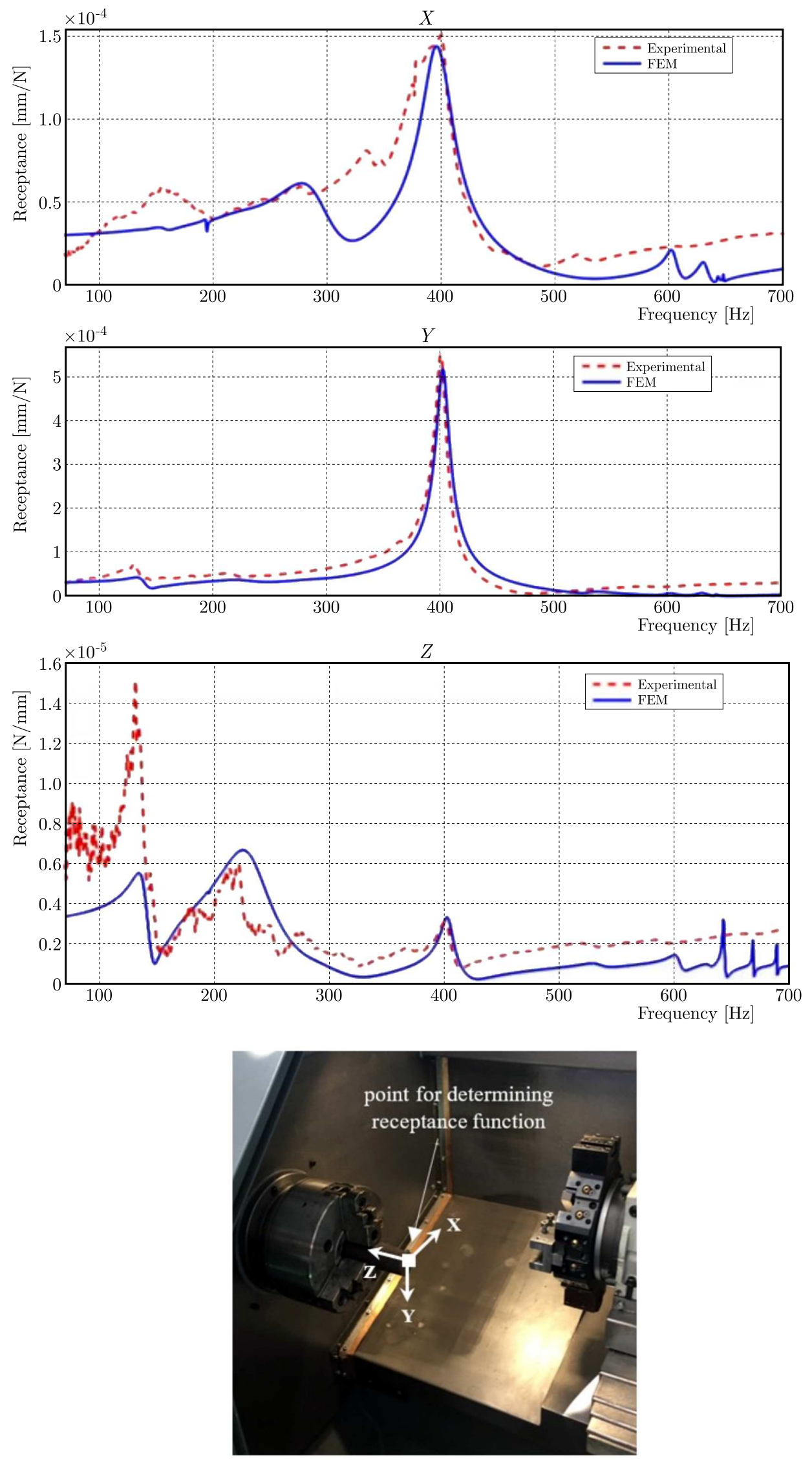

Fig. 10. Comparison of the receptance functions determined computationally and experimentally 
Table 5. Comparison of experimentally and computationally determined natural frequencies

\begin{tabular}{|l|c|c|}
\hline Preload level & $k_{a}[[\mathrm{~N} / \mu \mathrm{m}]$ & $k_{r}[[\mathrm{~N} / \mu \mathrm{m}]$ \\
\hline \hline Middle & 617.00 & 1287.00 \\
\hline Extra light & 348.00 & 724.00 \\
\hline
\end{tabular}

To prove the accuracy of the model not only for the natural frequencies but also in terms of the frequency response function agreement, a comparison was made between the receptance functions determined computationally and experimentally at the end of the workpiece. A comparison of selected receptance functions is provided in Fig. 10.

When analyzing the amplitudes of the receptance functions, one can see their high agreement. Of particular importance is the ability of the developed computational model to map the amplitude of the dominant resonance in both the $X$ and $Y$ directions. This is extremely important for the potential analysis of the stability of machining (Jasiewicz and Miaddlicki, 2019; Hung et al., 2013).

\section{Conclusions}

This paper presents a procedure for modeling rolling bearings, the utilitarian nature of which is demonstrated through its application to the modeling of a lathe spindle. The developed modeling methodology allowed accurate prediction of dynamic properties of the analyzed spindle. This was confirmed experimentally by comparing values of the natural frequency, natural frequency form and the receptance function.

The proposed methodology is distinguished by its simplicity of application in a finite element model of a larger structure. Connections can be made using both selected contact and node coincidence models, which can be particularly attractive for computational analysis using reduction and substructuring methods.

In addition, its versatility has been demonstrated through modeling. More specifically, the proposed modeling methodology can be used to model both single ball or roller bearings and complex bearing blocks. In addition, the proposed methodology, using a two-part discrete model coupled together using bidirectional sliding contact, enables mapping of the free movement of the bearing in the axial direction.

A limitation of the modeling methodology used is the inability to represent the relative rotational motion between the outer and inner bearing rings around the shaft axis. This is directly related to the assumptions of the methodology and the use of an orthotropic material model. Low natural frequencies related to rotation may be distorted, however there were no disturbances in the conducted simulations in this study. Moreover, for bearings characterized by small contact angles and, at the same time, high $k_{\text {real }}^{a} / k_{\text {real }}^{r}$ ratio, the method is less accurate.

Acknowledgement

The research was carried out on research apparatus purchased as a part of project No. RPZP.01.03.0032-0004/17. The project was co-financed by the European Union from the European Regional Development Fund under the Regional Operational Program of the West Pomeranian Voivodeship 2014-2020. The project was co-financed by the Ministry of Science and Higher Education.

This study was supported by the Ministry of Education and Science, Poland Implementation Doctoral Programme, granted to Jan Tomaszewsk.

\section{References}

1. Allemang R.J., 2003, The modal assurance criterion - twenty years of use and abuse, Sound and Vibration, 37, 8, 14-23. 
2. Cao H., Li B., Li Y., Kang T., Chen X., 2019, Model-based error motion prediction and fit clearance optimization for machine tool spindles, Mechanical Systems and Signal Processing, 133, 106252

3. CaO H., Li Y., Chen X., 2016, A new dynamic model of ball-bearing rotor systems based on rigid body element, Journal of Manufacturing Science and Engineering, 138, 7

4. Cao H., Niu L., Xi S., Chen X., 2018, Mechanical model development of rolling bearing-rotor systems: a review, Mechanical Systems and Signal Processing, 102, 37-58

5. Cao Y., Altintas Y., 2007, Modeling of spindle-bearing and machine tool systems for virtual simulation of milling operations, International Journal of Machine Tools and Manufacture, 47, 9, $1342-1350$

6. Cao Y., Altintas Y., 2004, A general method for the modeling of spindle-bearing systems, Journal of Mechanical Design, 126, 6, 1089-1104

7. Guay P., Frikha A., 2015, Ball bearing stiffness. A new approach offering analytical expressions, Proceedings of 16th European Space Mechanisms and Tribology Symposium, Bilbao, 23-25

8. Gupta P.K., 1979, Dynamics of rolling-element bearings - Part IV: Ball bearing results, Journal of Lubrication Tribology, 101, 3, 319-326

9. GuYAn R.J., 1965, Reduction of stiffness and mass matrices, AIAA Journal, 3, 2, 380

10. Hu G., Zhang D., Gao W., Chen Y., Liu T., Tian Y., 2018, Study on variable pressure/position preload spindle-bearing system by using piezoelectric actuators under close-loop control, International Journal of Machine Tools and Manufacture, 125, 68-88

11. Hung J.-P., Lai Y.-L., Luo T.-L., Su H.-C., 2013, Analysis of the machining stability of a milling machine considering the effect of machine frame structure and spindle bearings: experimental and finite element approaches, International Journal of Advanced Manufacturing Technology, 68, 9-12, 2393-2405

12. JAsiewiCz M., MiądLiCKi K., 2019, Implementation of an algorithm to prevent chatter vibration in a CNC system, Materials, 12, 19, 3193

13. Jones A.B., 1960, A general theory for elastically constrained ball and radial roller bearings under arbitrary load and speed conditions, ASME Journal of Basic Engineering, 82, 2, 309-320

14. Lempriere B.M., 1968, Poisson's ratio in orthotropic materials, AIAA Journal, 6, 11, 2226-2227

15. Mul J.M. De, Vree J.M., MaAs D.A., 1989, Equilibrium and associated load distribution in ball and roller bearings loaded in five degrees of freedom while neglecting friction - Part I: General theory and application to ball bearings, Journal of Tribology, 111, 1, 142-148

16. Nelson H.D., 1980, A finite rotating shaft element using Timoshenko beam theory, ASME Journal of Mechanical Design, 102, 793-803

17. Neumark S., 1962, Concept of Complex Stiffness Applied to Problems of Oscillations with Viscous and Hysteretic Damping, HM Stationery Office

18. Peeters B., van der Auweraer H., Gulllaume P., Leuridan J., 2004, The PolyMAX frequency-domain method: a new standard for modal parameter estimation, Shock and Vibration, 11, 3-4, 395-409

19. Rantatalo M., Aidanpä̈̈ J.O., Göransson B., Norman P., 2007, Milling machine spindle analysis using FEM and non-contact spindle excitation and response measurement, International Journal of Machine Tools and Manufacture, 47, 7-8, 1034-1045

20. Ritou M., Rabréau C., Le Loch S., Furet B., Dumur D., 2018, Influence of spindle condition on the dynamic behavior, CIRP Annals, 67, 1, 419-422

21. Saint-Venant A.J.C. De, 1863, Sur la distribution des élasticités autour de chaque point d'un solide ou d'un milieu de contexture quelconque, particulièrement lorsqu'il est amorphe sans être isotrope, Journal de Mathématiques Pures et Appliquées, 8, 353-430 
22. Urbikain G., Olvera D., López de Lacalle N.L., Elías-Zúñiga A., 2016, Spindle speed variation technique in turning operations: modeling and real implementation, Journal of Sound and Vibration, 383, 384-396

23. Xi S., Cao H., Chen X., 2019, Dynamic modeling of spindle bearing system and vibration response investigation, Mechanical Systems and Signal Processing, 114, 486-511

24. Xi S., Cao H., Chen X, Niu L., 2018, Dynamic modeling of machine tool spindle bearing system and model based diagnosis of bearing fault caused by collision, Procedia CIRP, 77, 614-617

25. Xu K., Wang B., Zhao Z., Zhao F., Kong X., Wen B., 2020, The influence of rolling bearing parameters on the nonlinear dynamic response and cutting stability of high-speed spindle systems, Mechanical Systems and Signal Processing, 136, 106448

Manuscript received July 7, 2021; accepted for print September 12, 2021 